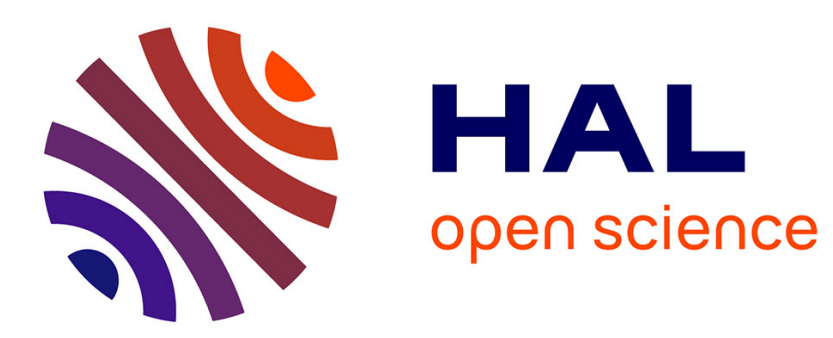

\title{
Collaborative platform for skin cancer screening and associated optical fibered probe for diagnosis
}

C. Pieralli, B. Wacogne, V. Bonnans, P. Humbert, L. Pazart, F. Marzani, J.C. Lapayre, C. Lang

\section{- To cite this version:}

C. Pieralli, B. Wacogne, V. Bonnans, P. Humbert, L. Pazart, et al.. Collaborative platform for skin cancer screening and associated optical fibered probe for diagnosis. Singaporean-French IPAL Symposium, Feb 2009, Singapour, Singapore. hal-00472303

\section{HAL Id: hal-00472303 https://hal.science/hal-00472303}

Submitted on 9 Apr 2021

HAL is a multi-disciplinary open access archive for the deposit and dissemination of scientific research documents, whether they are published or not. The documents may come from teaching and research institutions in France or abroad, or from public or private research centers.
L'archive ouverte pluridisciplinaire HAL, est destinée au dépôt et à la diffusion de documents scientifiques de niveau recherche, publiés ou non, émanant des établissements d'enseignement et de recherche français ou étrangers, des laboratoires publics ou privés.

\section{(c)(1)}

Distributed under a Creative Commons Attribution| 4.0 International License 


\title{
COLLABORATIVE PLATFORM FOR SKIN CANCER SCREENING AND ASSOCIATED OPTICAL FIBERED PROBE FOR DIAGNOSIS
}

\author{
CHRISTIAN Pieralli, BRUNO WACOGNE, \\ FEMTO-ST Institute, Optics Department, UMR CNRS 6174, 16, route de Gray \\ Besançon, 25030, France
}

VINCENT BONNANS, PHILIPPE HUMBERT

Federative Research Institute for Cellular and Tissue Engineering, University Hospital,

1, Place Saint Jacques

Besançon, 25000, France

LIONEL PAZART

Clinical Investigation Center for Technological Innovation, University Hospital, 1, Place Saint Jacques

Besançon, 25000, France

FRANCK MARZANI

Laboratory of Electronics, Computing Science and Image, UMR CNRS 5158, Université de Bourgogne, UFR Sciences et Techniques,Bât. Sciences de l'Ingénieur, Faculté Mirande

Dijon, 21000, France

JEAN-CHRISTOPHE LAPAYRE, CHRISTOPHE LANG

Laboratory of Computer Science, 16, route de Gray

Besançon, 25030, France 
The early screening and diagnosis is one of the most critical steps in the curing of skin cancers and mainly melanomas. We present here a complete platform which deals from screening to therapy via diagnosis in a collaborative manner. The screening is made with a computing collaborative platform consisting of a photograph of the incriminated skin region, its sending to a server devoted to image processing as an aid to the dermatologist who will examine the photograph and the results given by image processing. If there is a doubt, the patient will be proposed to go at a dermatologist's office for diagnosing the eventual cancer by using an optical probe developed in our laboratory. Then, in case of a cancer, the dermatologist will be able to cure the cancer by phototherapy by using the same optical probe.

\section{DeCoPreMe: a New Teleplatform for Early Detection of Melanomas}

\subsection{Introduction}

DeCoPreMe (Fr. Dépistage Collaboratif Précoce des Mélanomes, Eng. Precocious Collaborative Screening of Melanomas) is a computerized decisionmaking system dedicated to the dermatologists and particularly for the treatments of different melanomas. The frequency of skin cancers, which are in particular melanoma, has not ceased increasing for several decades. It is estimated that 1 person on 50 will be confronted with this diagnosis in 2010 .

Whereas an early tracking of the malignant melanoma followed by a surgical ablation allows a cure, a late diagnosis means a high morbidity and mortality. This is why the, since the beginning of the Nineties, dermatologists developed a technique of cutaneous microscopy of surface, the dermatoscopy, which allows a specific symptomatology to interpret the pigmented cutaneous links and to appreciably improve detection of the melanoma at an early stage.

The LIFC Lab. is a Computer Science research Lab. located in Besançon (France). This Lab. counts 80 researchers divided in 4 teams. The project team concerned with this project is focused on collaborative work and distributed systems: applied on telemedicine. This team is named CARTOON (Collaborative Architecture, Distributed Algorithms, Optimization, and Scheduling). LIFC works on telescreening, teleapplications, in particular diagnosis software and interfaces for mobile networks and PDAs [1]. LIFC develops projects with companies such as PSA, Schlumberger, Alstom, FranceTelecom, Parkeon. In this project, the laboratory has worked especially on network transmission, consistency of images, collaborative work tools for telescreening.

\subsection{DeCoPreMe System Description}

The DeCoPreMe platform offers the necessary tools and new technologies of communication and teleprocessing (cellular telephone, PDA, GSM, GPRS, Wifi, 
Bluetooth...) to carry out a numerical seizure of the lentingo (a kind of beauty spot) picture, its sending to experts who will make a fast diagnosis to the attention of the patient or the attending physician [2]. This technology will be accessible to the public via pharmacies, tracking buses and the consultations in the attending physician or in the hospital. It will thus bring a saving of time in the diagnosis process. This platform will be accessible to a large audience to allow an initial screening then a regular follow-up of the patients at the identified risks.

\subsection{Structure of DeCoPreMe System}

The DeCoPreMe system is composed particularly of:

1. Hardware system for the acquisition naevus images. This system is composed of a lens (which has its own lighting: Figure 1.) and a digital camera connected to the network. This lens can be plugged on a camera or plugged on a mobile phone,

2. The acquired image is transmitted to the French server,

3. A connection is established between the acquisition server (France) and the pretreatment server (Switzerland),

4. The pretreatment server for the diagnosis assistance presents all the tools required to detect the presence of a melanoma from the treated images like his class of membership: Class 1: risk melanoma, Class 2: no risk, Class 3: does not decide.

5. A bank of data to safeguard the medical images of the patients as well as the reports/ratios of the experts following the diagnoses carried out [3],

6. A distant engine of treatment is installed close the experts to establish the diagnosis according to pretreated images,

7. The practitioner is in connection with the central server of treatment as well as with the other experts in order to establish a diagnosis in collaboration and to send the result to the patient. Each engine of treatment is connected in the DeCoPreMe network and has access to the various files of the patients via the data bank data.

Two important aspects have to be pointed out:

- Network level: it is important to secure communications between servers. Protocols have been established between servers in order to maintain the anonymity of patients and secondly in order to maintain the reliability of transmitted data.

- Collaborative work level: LIFC is a specialist of collaborative teleapplications especially in the field of remote diagnosis. It is important to guarantee/ consistency of exchanged data, to manage their traceability and their archiving. 


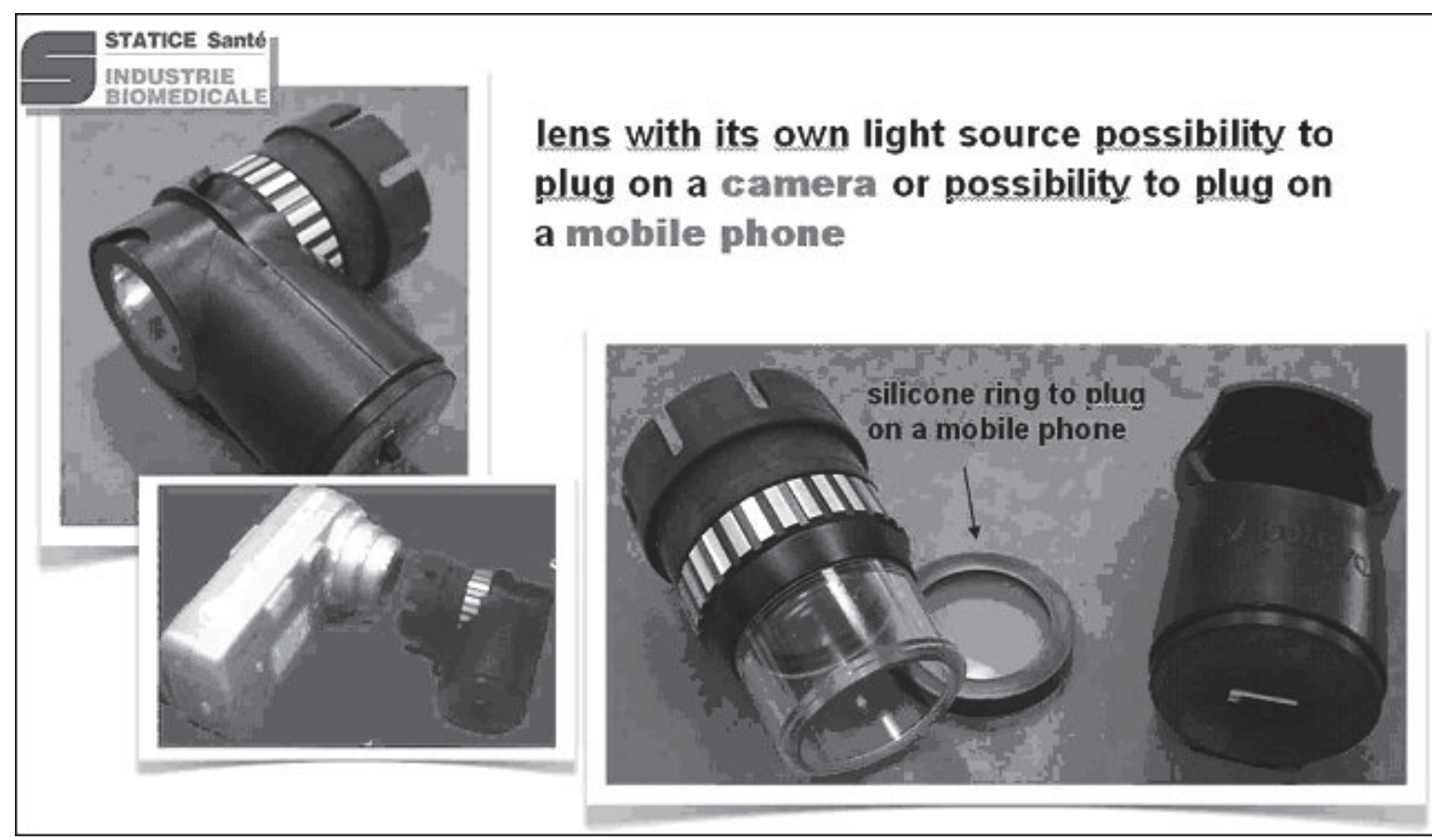

Figure 1. Lens prototype developed by the Statice Santé Compagny.

After this screening step, if there is a doubt, the patient will be proposed to go at a dermatologist's office to establish the diagnosis. This will be done with an optical probe which is depicted hereafter.

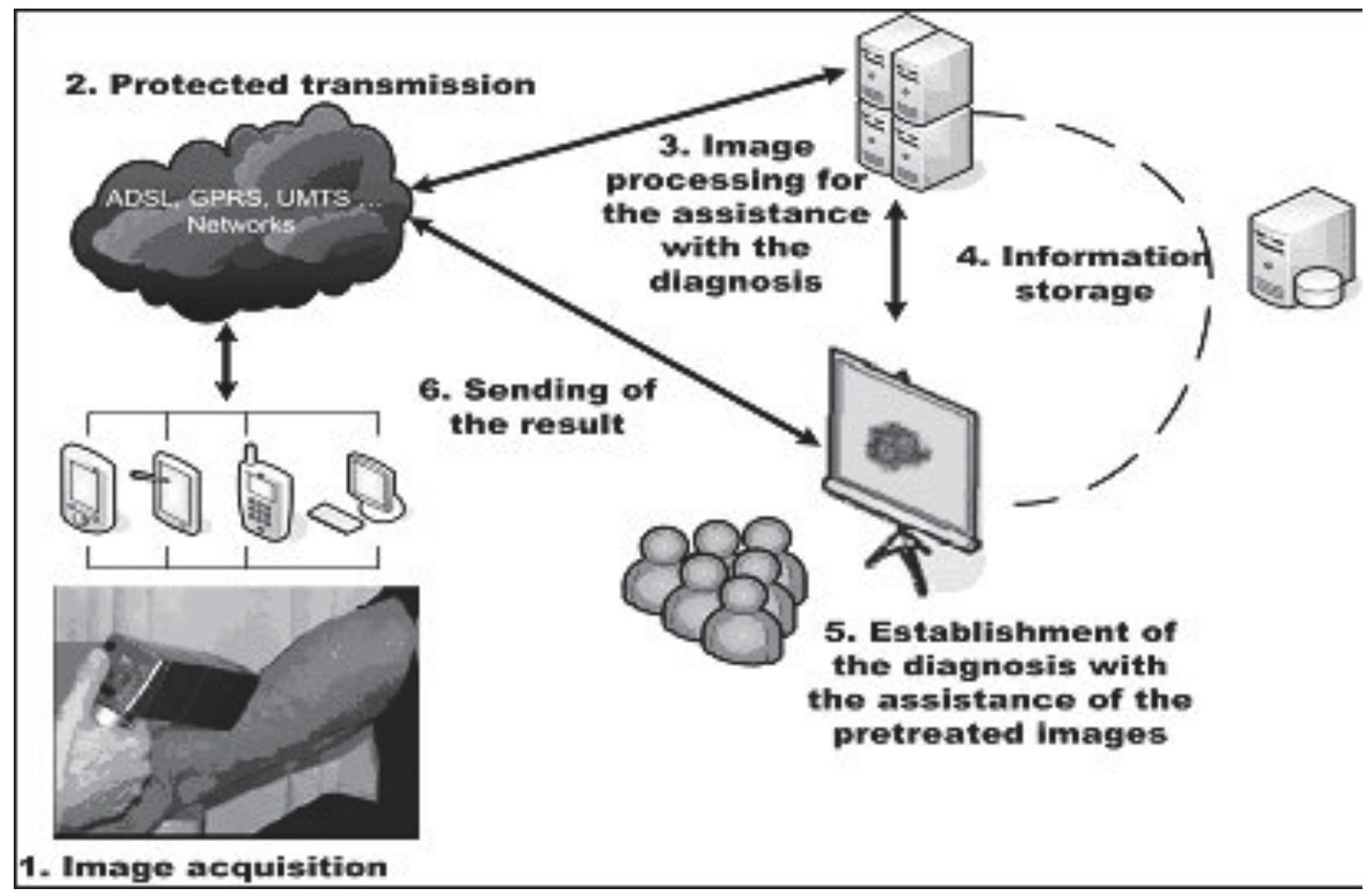

Figure 2. Structure of DeCoPreMe System. 


\section{Optical Probe for skin cancer diagnosis}

\subsection{Positioning of works in the context of the current knowledge}

Currently, from a technical viewpoint, the objective methods of diagnosis of the melanomas rely on the use of expensive apparatuses (intensified cameras for example) or relatively cheap ones but exhibiting low spatial resolutions [4][5][6][7][8]. Moreover, these methods allow detecting a malignant tumor when this one has already reached a relatively important size (belated detection). This asks about the problems of realizing a biopsy to confirm the diagnosis or to remove the tumor, surgical gesture greatly invasive.

The technique we propose to validate allows precociously detecting the tumors since the spatial resolution of our probe is lower than the dimension of a skin cell. Then, it becomes possible to detect a malignant tumor to the level of a unique cell. Besides, since the detection is based on an optical probe, it is simultaneously foreseeable to destroy the malignant cells by using dynamic phototherapy [9][10][11]. That is to say that it would not be necessary to practice biopsies anymore, the diagnosis and the therapy being conducted rapidly at the same time.

Another aspect that distances our project from the expensive or imprecise systems on the market [12][13], resides in the double measurement of the fluorescence intensity, but also of its decay time. The association of these two types of measurements is unique and would allow improving the diagnosis and differentiating different types of tumors by analyzing the decay time.

With regard to the competitive positioning, it does not exist (at present) any equivalent to this research. Concerning the diagnosis, the state of the art concerns the biopsies, the image processing, the localized measurement of the fluorescence intensity and various methods using laboratory devices. This confers an incontestable asset to the project.

\subsection{Detailed description of the methodology and techniques employed}

Our previous works concerned the set up of a particular optical system that guaranteed a very good quality of detection of the fluorescence signals (tip of the probe) on one hand, and on the other hand on the set up of the actual probe (tip and micromechanical scanning device) in collaboration with the DA society of Rioz (France).

We have proposed an innovating approach based on the use of a miniaturized fiber sensor of $2 \mathrm{~mm}$ in diameter, associated to a suitable scanning system. This new approach required the development of a small, unpublished 
scanning system. This system palliates the problems of scanning speed, main drawback of the existing devices.

The work consisted in simulating this new type of sensor to find an optimized solution to the problem. This stage of simulation has been achieved in narrow collaboration with the laboratory of engineering and cutaneous Biology of the Prof. Humbert (CHU Besançon), to take into account the constraints imposed by use of this type of device in vivo. In parallel the study of the scanning system leaded to collaboration with a society of micromechanics. Unfortunately, the mechanics proved to be fragile and a new one must be manufactured during this project.

The second work consisted of the realization of the sensor for characterization (figure 3).

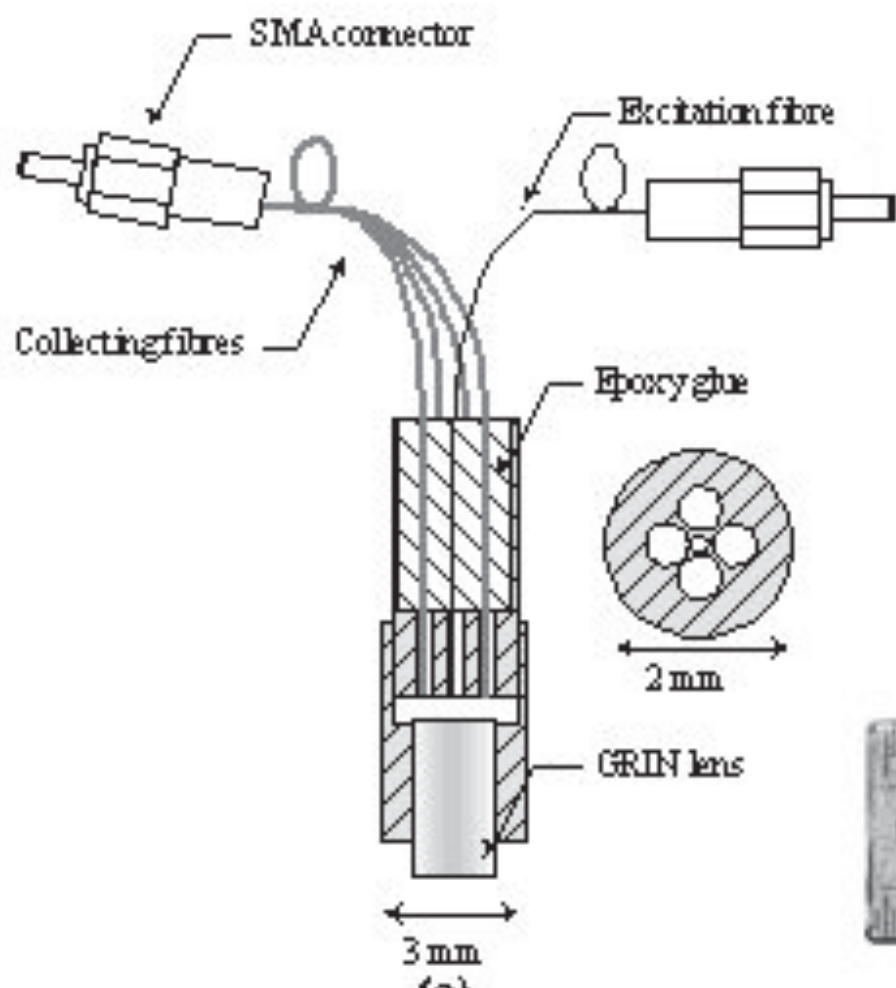

(a)
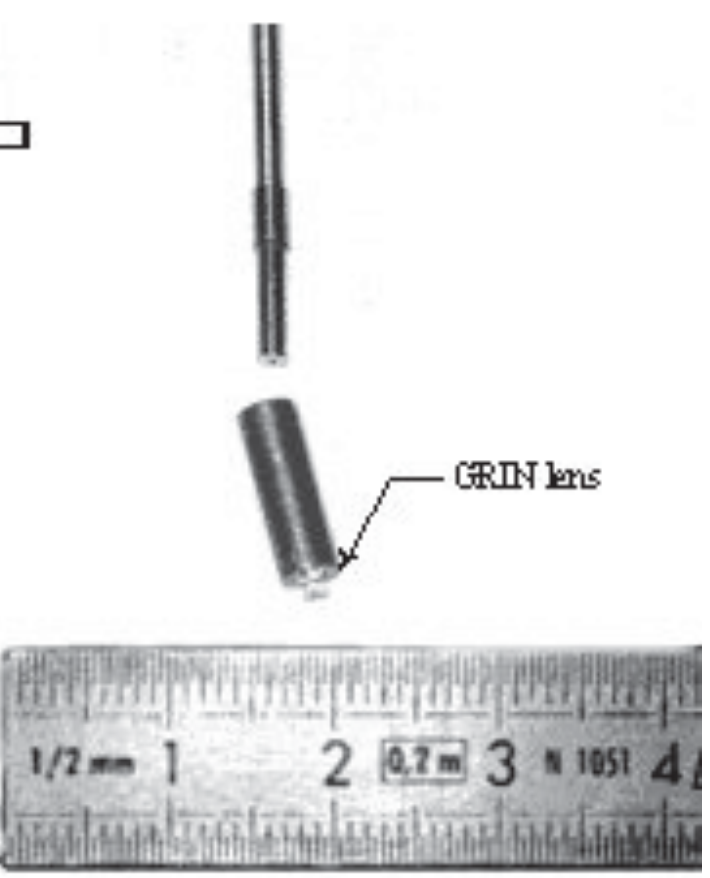

(b)

Figure 3. Schematic diagram of the sensor.

The laser light issued from a violet laser diode [14] is injected in a conventional optical fiber (core diameter $2.7 \mu \mathrm{m}$ ) and is then guided to the skin area which has to be investigated. The skin cells will spontaneously re-emit a fluorescence signal (in fact, it is a protein, Protoporphyrin IX, PPIX) [15]. The amount of the fluorescence intensity can be discriminating because cancerous cells stores in a high quantity PPIX. The signal is detected with a photomultiplier (PM).

The complete measurement system demonstrated that the lateral resolution of our probe is $2 \mu \mathrm{m}$ on the pictures in fluorescence intensity and that the 
temporal resolution is $1 \mathrm{~ns}$ on the pictures in fluorescence decay time. Indeed, the device allows simultaneously measuring the intensity and the decay time (heterodyne measurement).

The physical principle of the fluorescence decay time measurement is simple: when a set of molecules exhibiting fluorescence properties is excited with a light pulse, the intensity of the emitted fluorescence (I) follows a decreasing exponential law with respect to the time:

$$
I(t)=I_{0} \operatorname{esp}(-t / \tau) .
$$

with $\tau$, the fluorescence decay time and $I_{0}$ the fluorescence intensity at $t=0$.

The fluorescence intensity gives information on the fluorophore concentration, while the decay time gives information on the chemical nature of the excited molecules as well as their neighborhood. Any fluorescent molecule has its own fluorescence decay time. Therefore, this measurement gives complementary information to the information given by the intensity.

In our application, the fluorescence decay times were short (1 to $20 \mathrm{~ns}$ ). Hence, we used a method based on the phase mismatch $(\phi)$ between the excitation (modulated at the frequency f) and the fluorescence emission. With this method, the decay time is given by:

$$
\tau=\frac{\tan (\phi)}{2 \pi f} .
$$

Without entering the details, figure 4 shows the experimental arrangement required for a decay time measurement with our probe. 


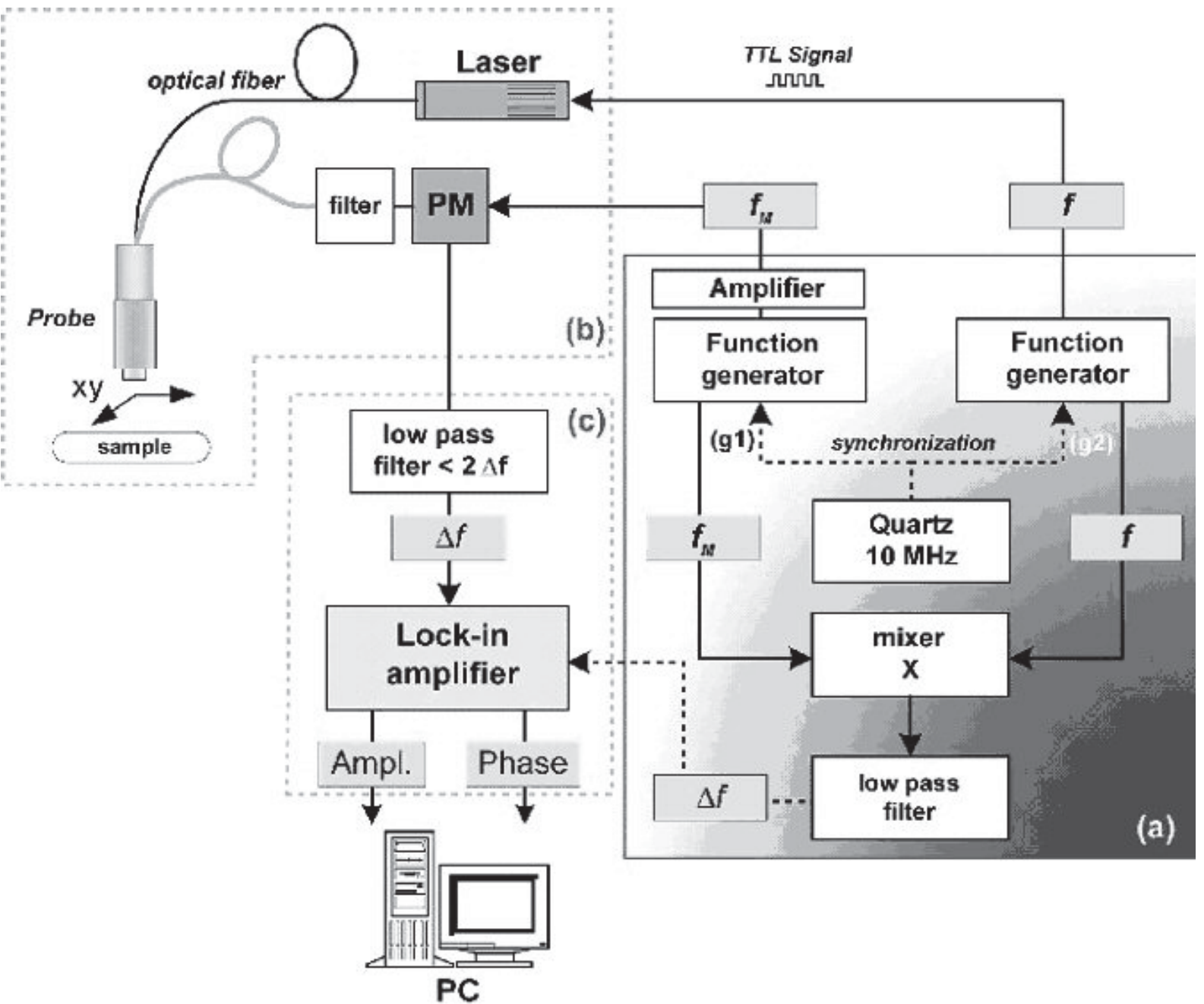

Figure 4. Experimental arrangement required for a decay time measurement with our probe.

The characterization of our sensor has been made with artificial and biological samples (tree leaves).

Two types of experiments have been conducted with artificial samples. The first ones were done with micro machined samples. A micro-photo-lithographic process has been used to define microscopic fluorescent structures. These structures were made with a polymer doped with protoporphyrine IX (PpIX). We chose this molecule because it is naturally present in the skin cells in which it plays the role of cancer indicator. These experiments allowed simulating the in vivo detection and estimating the spatial resolution of the system. The second ones were done with fluorescent latex micro spheres. They were marked with different fluorophores. Their diameters range from 2 to $15 \mu \mathrm{m}$. Their fluorescence decay times depend on the fluorophore used to mark them. Therefore, these types of samples were perfectly adapted to test the decay time resolution of our system as it is shown in figure 5 . 
(a)

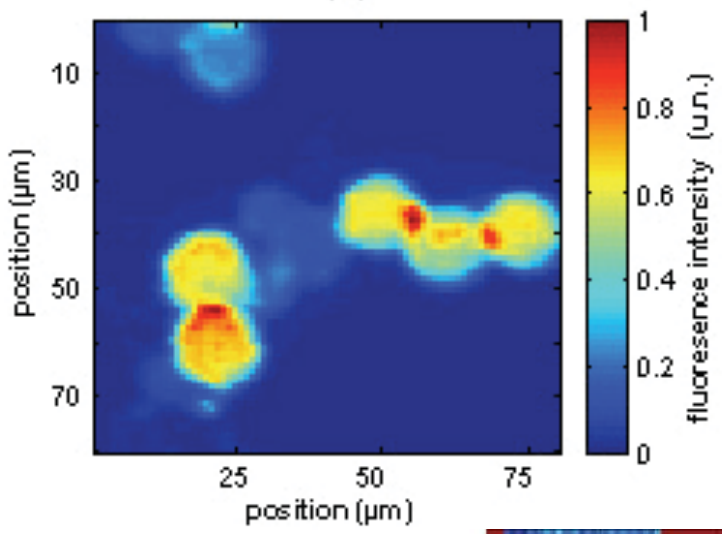

(b)

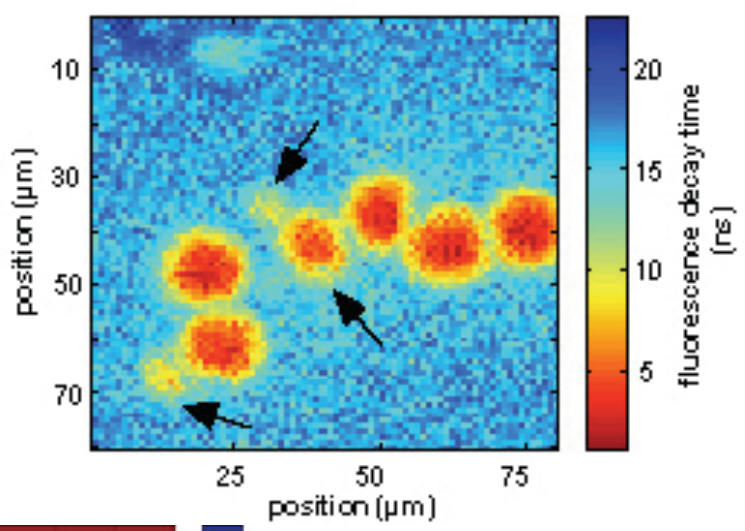

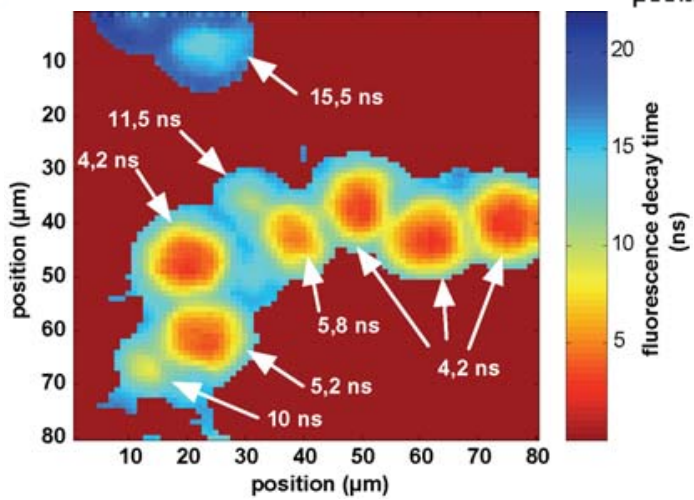

Figure 5. 80*80 pixels images obtained with our system. (a) Fluorescence intensity image at $630 \mathrm{~nm}$. (b) Decay time image. (c) Decay time differentiation between various latex micro spheres.

Concerning the tests on biological samples, we chose to measure the fluorescence of the chlorophyll-A of tree leaves [16]. This molecule is very attractive for our application because its fluorescence properties are very close to those of the protoporphyrin IX. These experiments permitted us to better understand the diffusion of the fluorescence in the tissues as well as the photobleaching mechanism in the biological samples (photobleaching $=$ loss of fluorescence properties due to a too intense excitation).
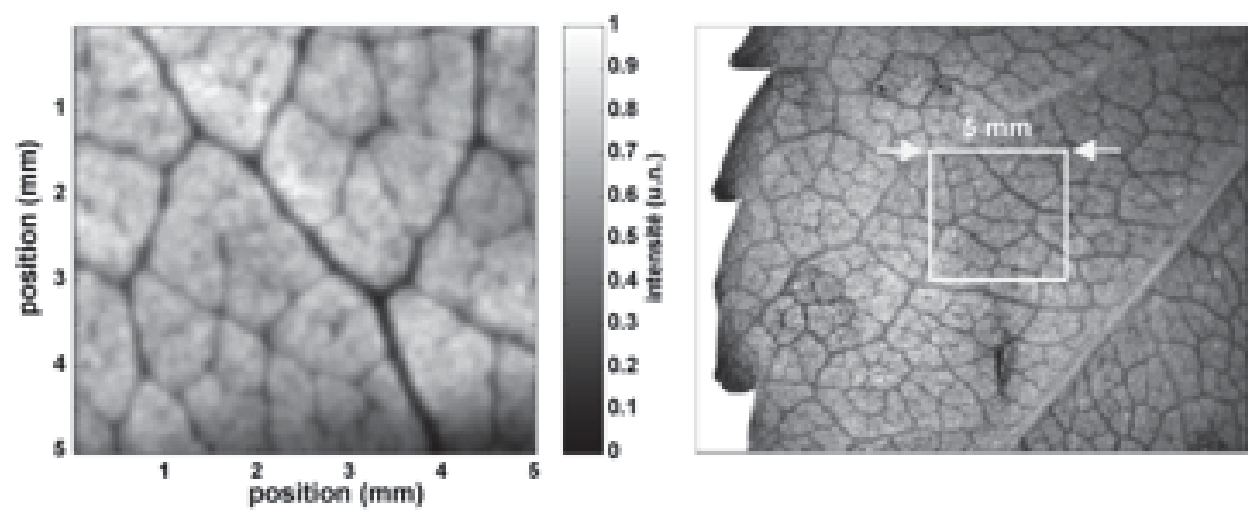

Figure 6. Fluorescence intensity image of a leaf $(630 \mathrm{~nm})$. (a) intensity image. (b) Region of interest.

This work must be continued with the in vivo study of the human skin fluorescence together with the integration of the probe into a new mechanical scanning system (figure 7). 


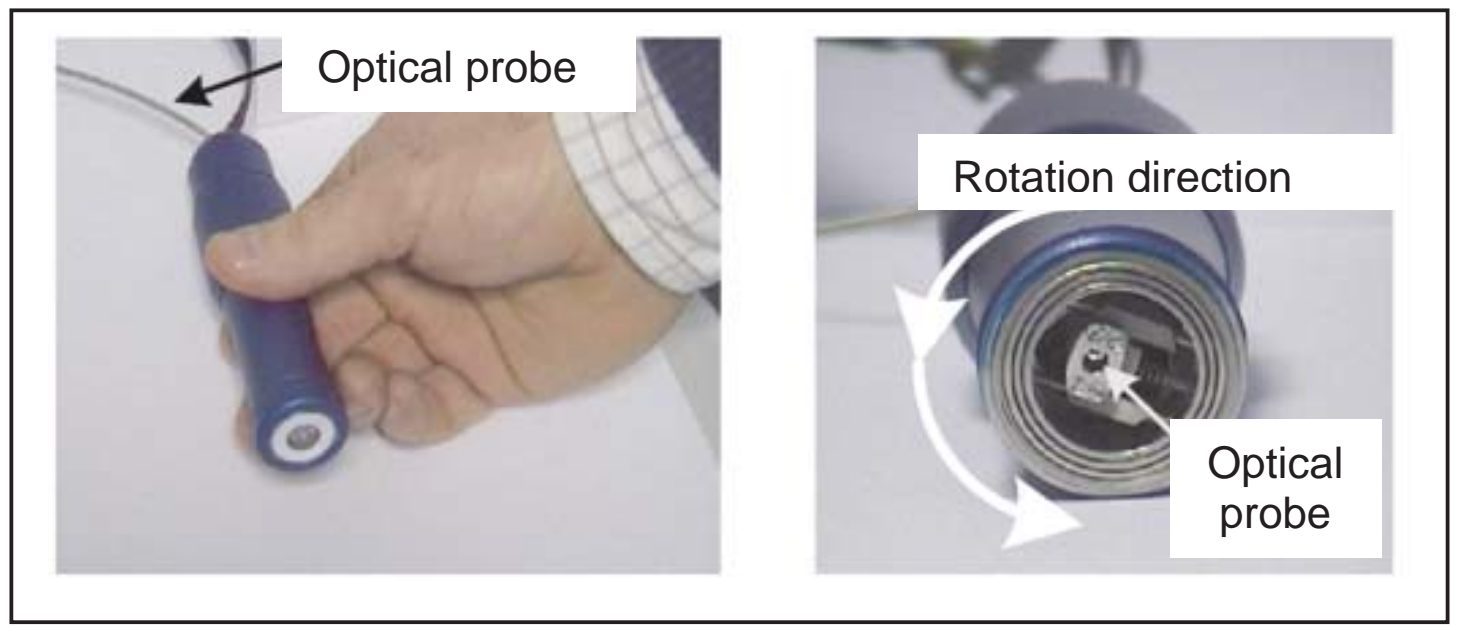

Figure 7. Pictures of the first probe prototype fabricated by the society Developpement Application. This system was found to fragile for a possible commercialization.

We have defined an experimental protocol to test the optical probe on six mice inoculated with malignant cells (figure 8). The aim of this experiment was to demonstrate the effectiveness of our sensor for pathologic cases. The tests were particularly successful and we observed that the decay time was about $5 \mathrm{~ns}$ for normal cells while it was about $10 \mathrm{~ns}$ for malignant cells. Moreover, the decay times we measured for malignant cells were the same for the six mice we tested. This result tends to prove the efficiency of our system for histological characterization of tissues.
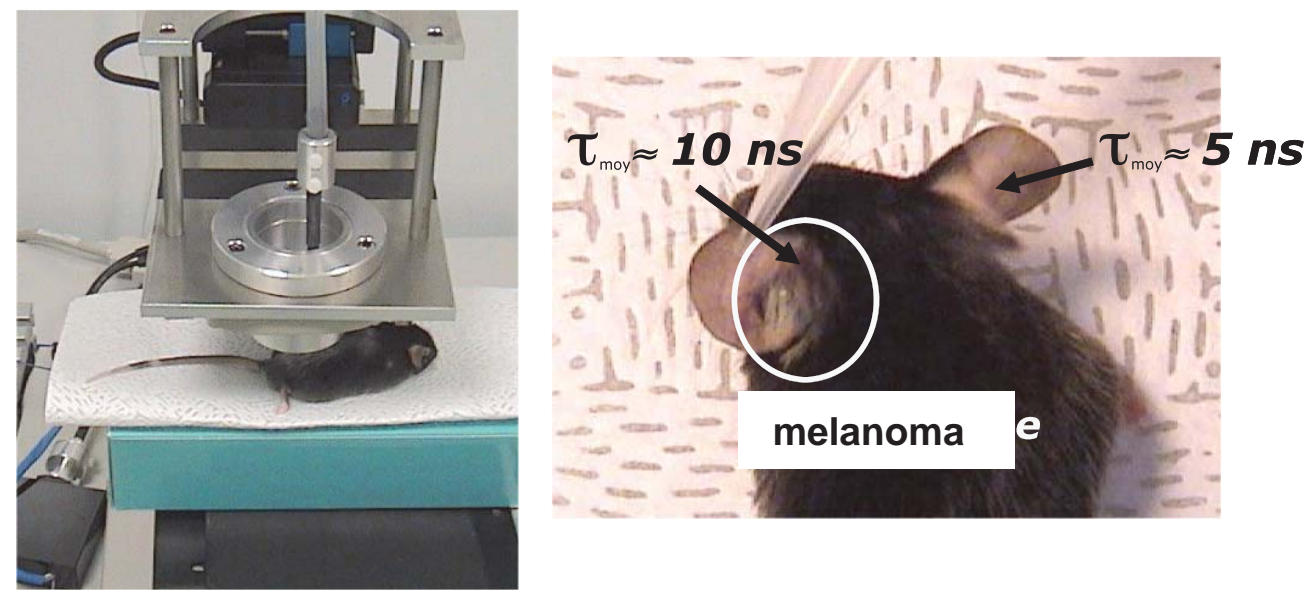

Figure 8. Experimentation of the probe on mice.

\section{Conclusion}

The feasibility of the DeCoPrem project and of the optical probe has been done.

Concerning DeCoPrem specifically, the next step is to build up the network between all intervening partners.

Concerning the optical probe various steps of the scientific domain should still be passed: 
1. Technical validation of the discrimination between normal and malignant cells in the domain of the fluorescence intensity.

2. Fabrication of a more robust scanning micro-mechanical system.

3. Optical treatment of tissues, also called "optical biopsies". This photodynamic therapy is still to be demonstrated.

At the end of this phase, it is foreseen that tests will be made on patients exhibiting a suspicious naevus, detected according to the recommendations of the HAS (visual analytical method comparable to the ABCDE rule, the revised list of 7 points of the Glasgow group or a visual cognitive method) and for whose an exaeresis biopsy (surgical act for totally removing infected, cancerous tissues) will have been recommended.

However, the aim of the global project is effectively to propose an alternative to the current steps for skin cancer: visual inspection, biopsy, biopsy study and then curing. This presents two main drawbacks: slowness, surgical misuse of the biopsy if the naevus is not cancerous. We propose a complete, fast and painless total treatment of skin cancers.

\section{References}

1. N. Elmarzouqi, E. Garcia, and J.-C Lapayre, Special issue on CSCWD Best Papers, LNCS Journal, Springer, (To appear in 2009).

2. D. Fuin, E. Garcia, H. Guyennet, and J.-C. Lapayre, Int. Journal on HighPerformance Computing and Networking (IJHPCN), (To appear in 2009).

3. C. Chemak, M.-S. Bouhlel, J.-C. Lapayre, and F. Kammoun, MCSEAI'O6, 9ème Maghrebian Conference on Software Engineering and Artificial Intelligence, Agadir Morocco, 324 (2006).

4. S. Andersson-Engles, G. Canti and R. Cubeddu, Laser Sur. Med. 26, 76 (2000).

5. S. Andersson-Engles, C. Klinteberg, K. Svangberg and S. Svanberg, Phys. Med. Biol. 4, 815 (1997).

6. H. Hewett, T. McKecnie, W. Sibbett and J. Fergusson, J. Mod. Opt. 47, 2021 (2000).

7. A.-M Wennberg, F. Gudmundson, B. Stenquist, A. Ternesten, L. Mölne, A. Rosen and O. Larkö, Acta Derm. Venereol. 79, 54 (1999).

8. X. Gao, Y. Cui, R. M. Levenson, L. W. K. Chung and S. Nie, Nature Biotech. 22, 969 (2004).

9. R.-M. Szeimies, C. A. Morton, A. Sidoroff and L. R. Braathen, Acta Derm. Venereol. 85, 783 (2005).

10. R. F. V. Lopez, N. Lange, R. Guy and M. V. Lopes Badra Bentley, Adv. Drug Deliv. Rev. 56, 77 (2004).

11. J. Hewett, V. Nadeau and J. Fergusson, Photochem. Photobiol. 73, 278 (2001).

12. J. M. Girkin and A. I. Ferguson, Opt. Express 7, 336 (2000).

13. K. Svanberg, I. Wang, S. Colleen and I. Idwall, Acta Radiol. 39, 2 (1998). 
14. N. M. Johnson, A. V. Nurmikko and S. P. DenBaars, Phys. Today 31, 31 (2000).

15. K. König, A. Rück and H. Schneckenburger, Opt. Eng. 31, 1470 (1992).

16. M. S. kim, J. E. McMurtrey. C. L. Mulchi, C. S. T. Daughtry, A. W. Chappelle and Y. R. Chen, Appl. Opt. 40, 157 (2001). 